Supporting Information

\title{
Synthesis of Ultrathin Si Nanosheets from Natural Clays for Lithium-Ion Battery Anodes
}

\author{
Jaegeon Ryu, Dongki Hong, Sinho Choi, and Soojin Park*
}

Department of Energy Engineering, School of Energy and Chemical Engineering, Ulsan National Institute of Science and Technology (UNIST), Ulsan 689-798, South Korea

*Corresponding Authors:

Soojin Park, spark@unist.ac.kr 


\section{Control of molten salt-assisted exfoliation of clay minerals}

Most of layered structures (e.g., montmorillonite, kaolinite, muscovite, etc.) have cationexchange capacity. ${ }^{1}$ These materials can be intercalated by various materials such as metal oxides, ${ }^{2}$ chlorides, ${ }^{3}$ salts ${ }^{4}$ and polymers. ${ }^{5}$ If the salts with high melting points and larger size are used, only partial destruction of clay minerals or severe damage on clay itself will take place. Therefore, salts with appropriate melting points should be chosen.

Treatment of clay minerals with molten salt (lithium nitrate, $\mathrm{LiNO}_{3}$ ) produced random interstratification of spacing from $2.1 \mathrm{~nm}$ depending on the reaction temperatures, as characterized by high-power XRD measurement (Fig. S4a). Bare clay minerals intercalated by alkyl amine show peaks at $4.12^{\circ}(001)$ and $6.94^{\circ}(002)$, corresponding to spacing of 2.1 $\mathrm{nm}$. After a mixture with stoichiometric molar ratio (clay : $\mathrm{LiNO}_{3}=1: 120$ ) is heated to 250 ${ }^{\circ} \mathrm{C}$ (melting point of $\mathrm{LiNO}_{3}$ ), its microstructure is not different from non-treated clay minerals (Fig. S4b). Rather, it shows smaller spacing $(2.0 \mathrm{~nm})$ with lower intensity and missing (002) peak, owing to malfunctioning of molten salts. This temperature $\left(250{ }^{\circ} \mathrm{C}\right)$ cannot fully activate and make the salt mobilized freely in this system. In case of higher reaction temperature $\left(280{ }^{\circ} \mathrm{C}\right.$ and $\left.320^{\circ} \mathrm{C}\right),(001)$ characteristic peaks completely disappeared from the XRD pattern (Fig. S4a), indicating that clays were randomly disordered or exfoliated with couple of layers stacked (Fig. S4c and S4d). Eventually, we obtained clearly exfoliated and thinner clay minerals at $320{ }^{\circ} \mathrm{C}$ by optimizing molten salt-assisted exfoliation process (Fig. 4d). In addition, we tested dispersion stability of different clays in suitable solvents. If they cannot make stable dispersion in non-polar chloroform solvent, these clays was not sufficiently exfoliated. Four types of clays including bare and the exfoliated at three different temperatures $\left(250{ }^{\circ} \mathrm{C}, 280{ }^{\circ} \mathrm{C}\right.$, and $\left.320{ }^{\circ} \mathrm{C}\right)$ were made with concentration of $2 \mathrm{mg} / \mathrm{mL}$ solution (Fig. S5). First row of photographs shows the clay solutions immediately after sonication for $30 \mathrm{~min}$. At early stage, all the dispersions looked stable. However, other 
dispersions except the clays exfoliated at $320{ }^{\circ} \mathrm{C}$ were precipitated out after $30 \mathrm{~h}$. It indirectly shows that exfoliation was successfully achieved in great extent at $320{ }^{\circ} \mathrm{C}$ and extremely thinner sheets of phyllosilicates were stabilized by solvent, while others had interior interaction sites not to be stabilized. Along with the exfoliation results by $\mathrm{LiNO}_{3}$, other alkali metal nitrates such as $\mathrm{NaNO}_{3}$ and $\mathrm{KNO}_{3}$, which have higher melting point than $\mathrm{LiNO}_{3}$, can also be used as intercalation agents. ${ }^{4}$ Although both $\mathrm{NaNO}_{3}$ and $\mathrm{KNO}_{3}$ require much more energies $\left(350{ }^{\circ} \mathrm{C}\right.$ and $\left.380{ }^{\circ} \mathrm{C}\right)$ and reaction times $(20 \mathrm{~h}$ and $48 \mathrm{~h})$, respectively, due to their larger size and strong ionic bonding, they show similar results. A clear exfoliation was observed in case of $\mathrm{NaNO}_{3}$ (Fig. S6a), but aggregated huge particles were existed in $\mathrm{KNO}_{3}$ case (Fig. S6b). Considering all the aspects, $\mathrm{LiNO}_{3}$ is recognized as the most effective molten salt for delaminating the clay minerals. 

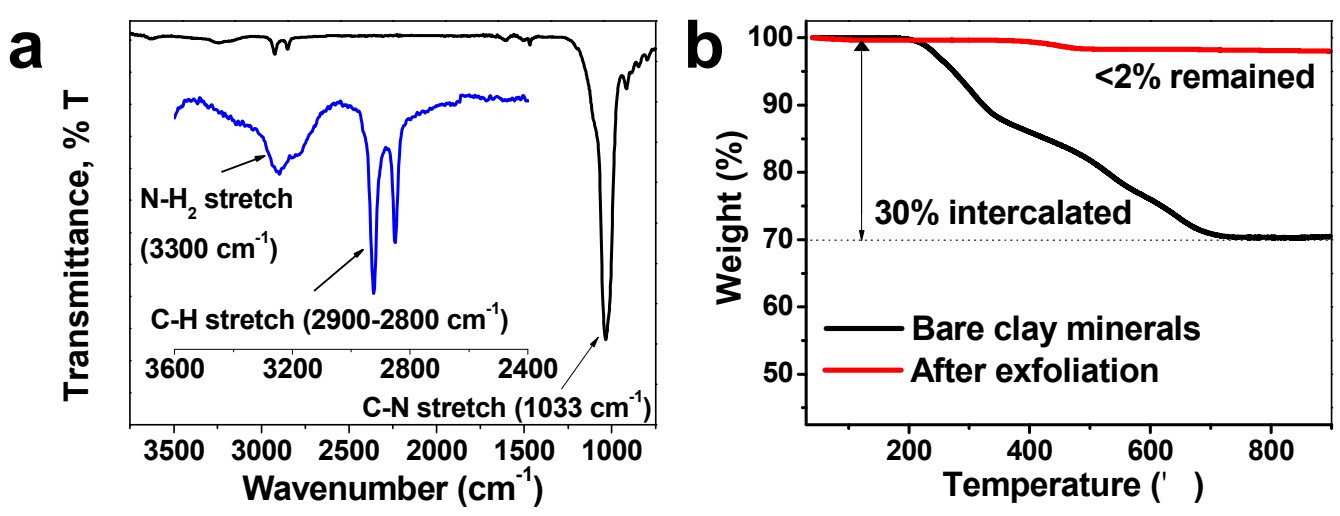

Figure S1. Analysis for intercalated primary alkyl amines. (a) Fourier-transform infrared spectroscopy (FT-IR) of bare clay minerals and (b) thermogravimetric analysis (TGA) of bare clay minerals and after exfoliation by molten salt.

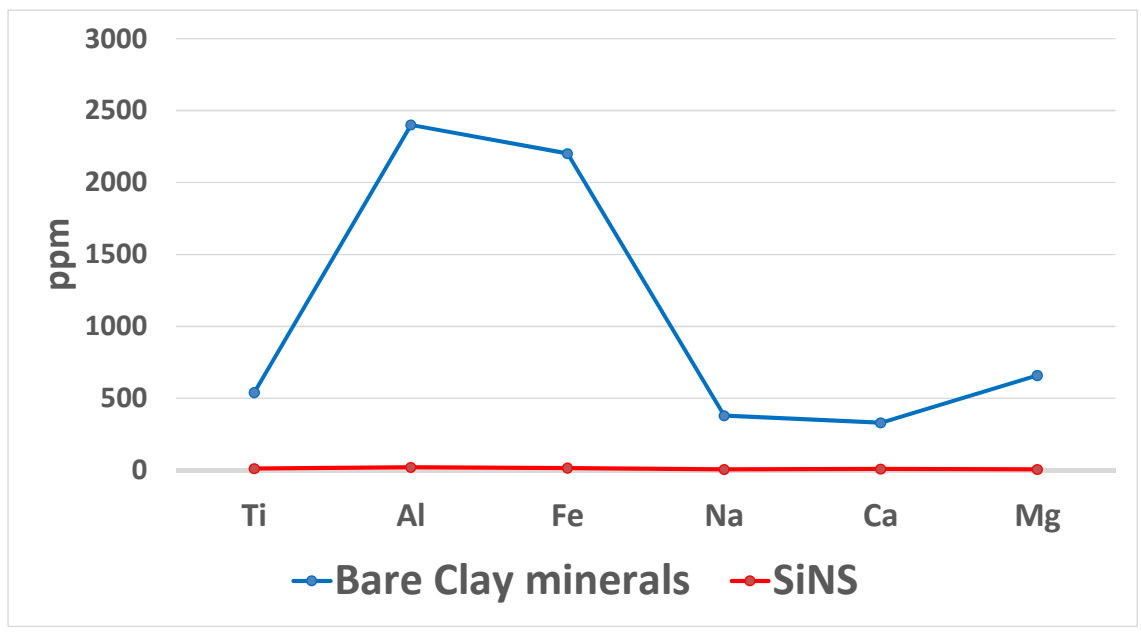

Figure S2. ICP analysis of pristine clay minerals and as-synthesized Si nanosheets. 

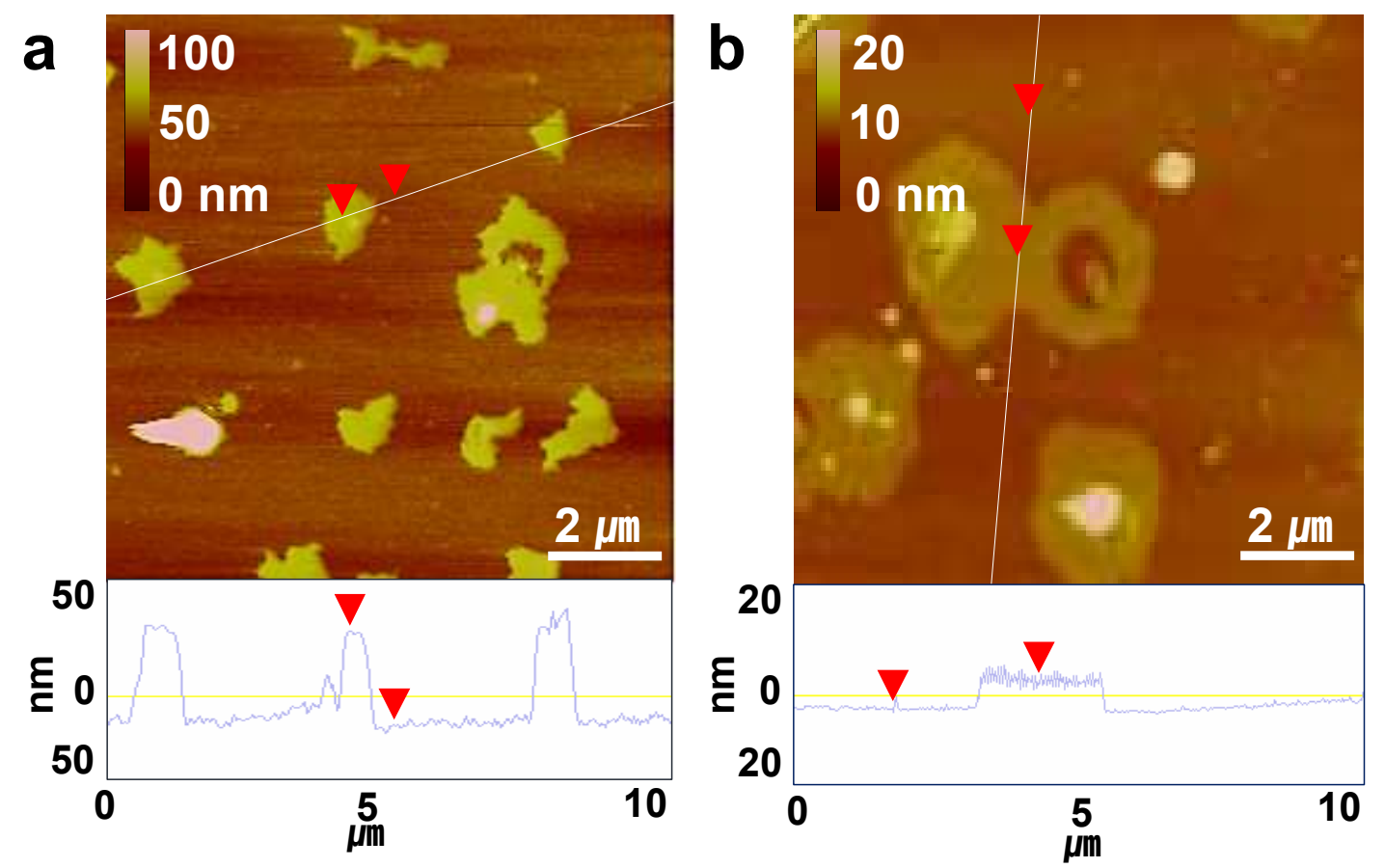

Figure S3. AFM analysis for bare and exfoliated clays. AFM images and cross-sectional height profiles of (a) bare clays and (b) clays exfoliated by molten-salt $\left(\mathrm{LiNO}_{3}\right)$ at $320{ }^{\circ} \mathrm{C}$. 

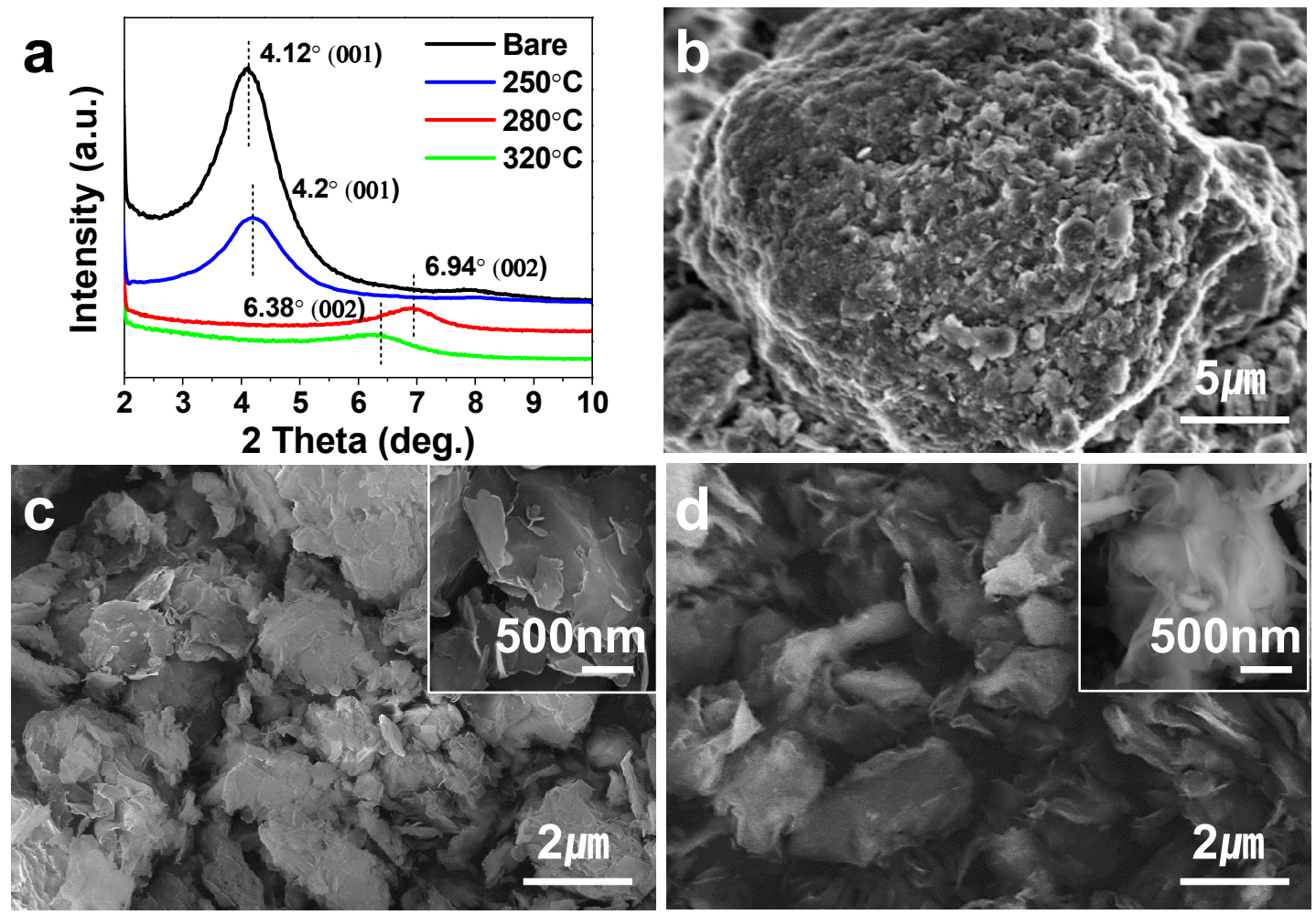

Figure S4. Chemical exfoliation of clay minerals. (a) High power XRD patterns and (b-d) SEM images of clay minerals exfoliated by molten salt $\left(\mathrm{LiNO}_{3}\right)$ at three different temperatures $\left(250{ }^{\circ} \mathrm{C}, 280{ }^{\circ} \mathrm{C}\right.$, and $\left.320{ }^{\circ} \mathrm{C}\right)$ at a fixed reaction time of $12 \mathrm{~h}$. Inset in each figure show magnified SEM images. 


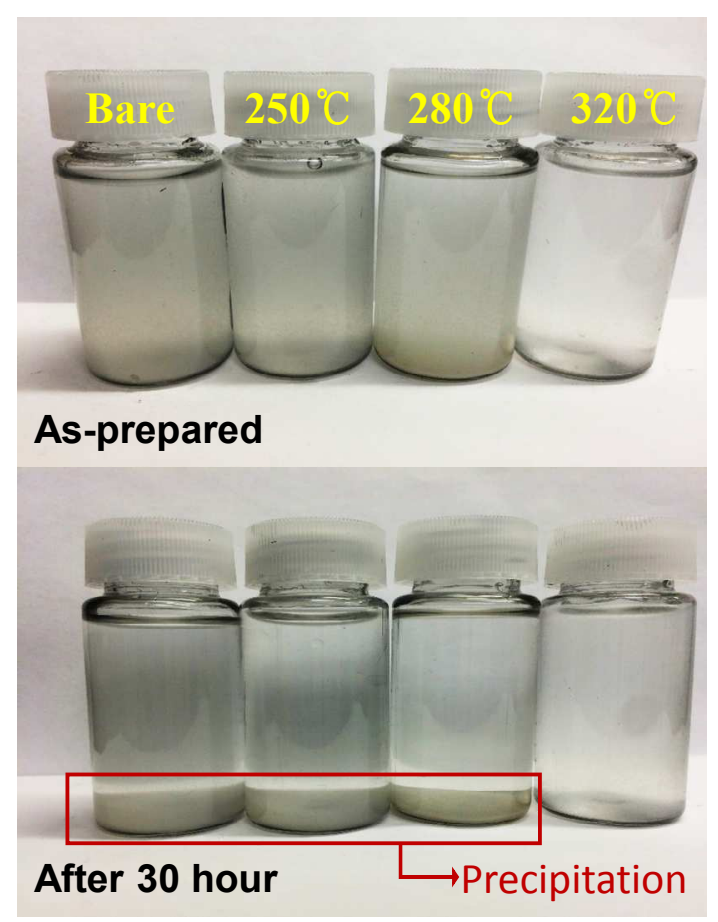

Figure S5. Photographs showing different dispersion properties of bare and clays exfoliated at three different temperatures $\left(250{ }^{\circ} \mathrm{C}, 280{ }^{\circ} \mathrm{C}\right.$, and $320{ }^{\circ} \mathrm{C}$ from left to right) Concentration of clay solution was fixed at $2 \mathrm{mg} / \mathrm{mL}$ in chloroform. Upper row shows as-prepared clay solutions, while bottom shows dispersion properties after staying for $30 \mathrm{~h}$.
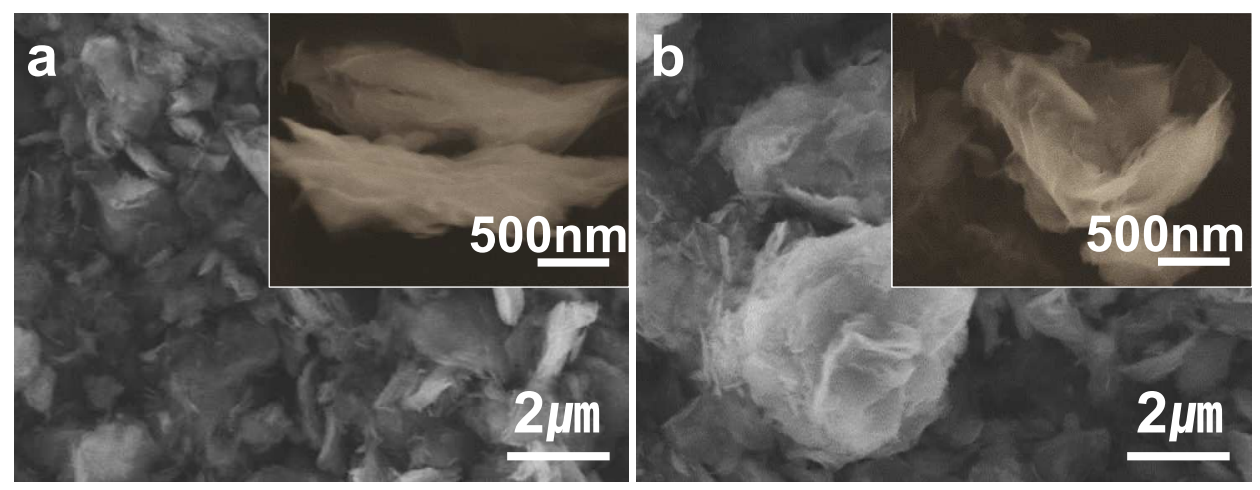

Figure S6. Exfoliation test by other molten salts. SEM images of clays exfoliated by (a) $\mathrm{NaNO}_{3}\left(350{ }^{\circ} \mathrm{C}\right.$ for $20 \mathrm{~h}$ ) and (b) $\mathrm{KNO}_{3}\left(380{ }^{\circ} \mathrm{C}\right.$ for $\left.48 \mathrm{~h}\right)$. Insets show corresponding high magnified SEM images. 


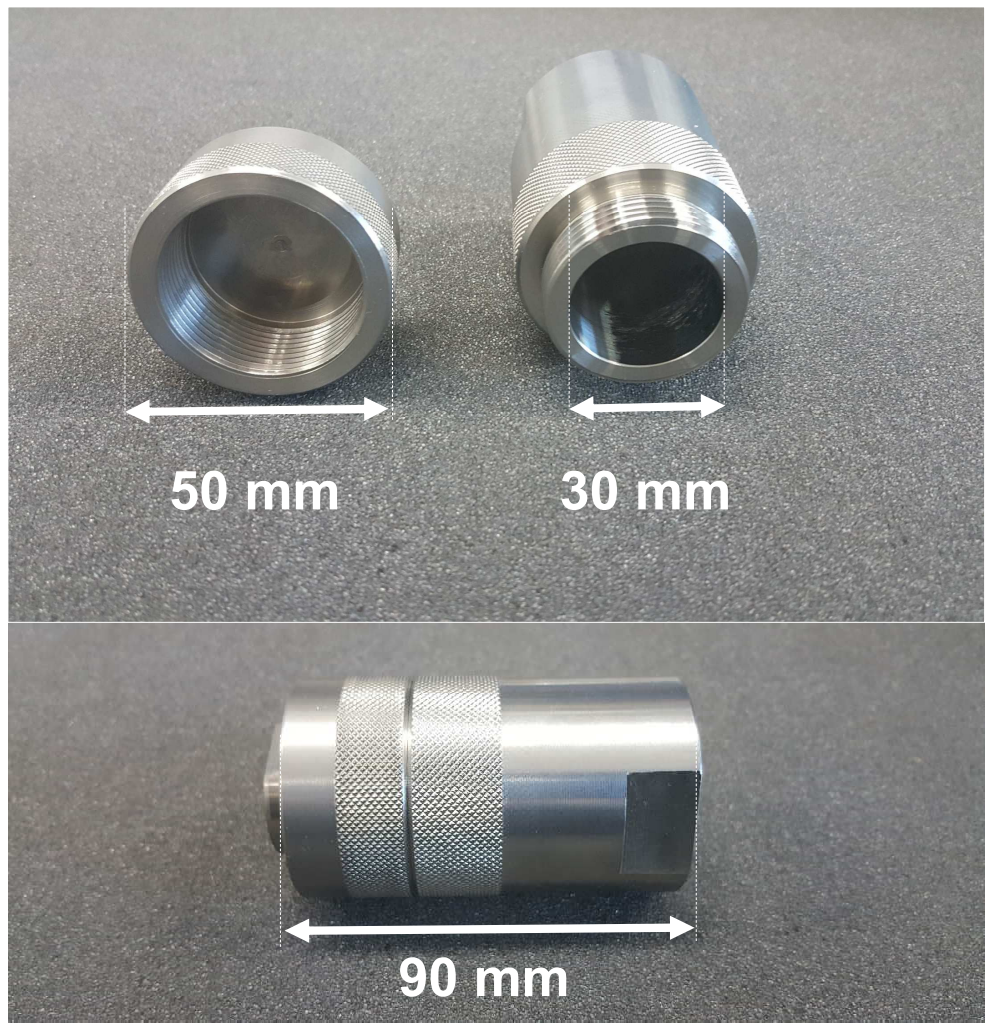

Figure S7. Photographs of home-made stainless steel reactor used for $\mathrm{Mg}$ reduction. 

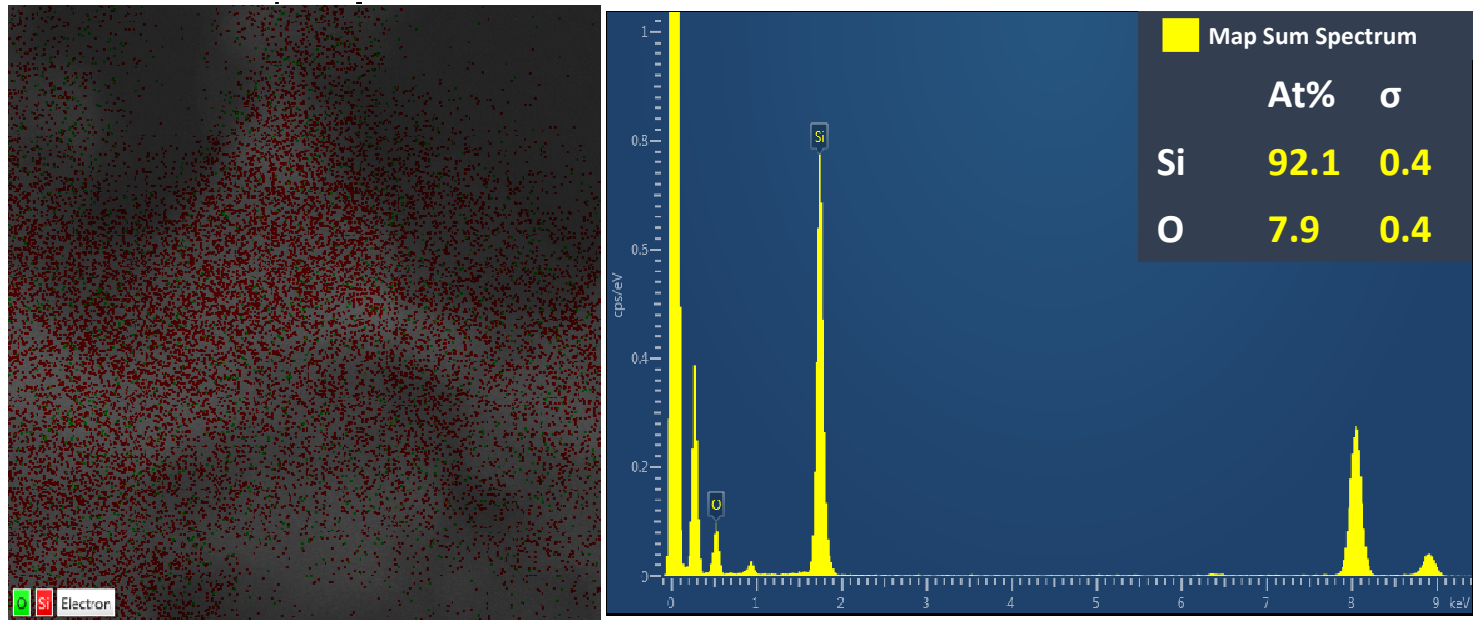

Figure S8. EDS mapping and spectrum of as-prepared SiNSs corresponding to bright-field HR-TEM image seen in Fig. 2b. 


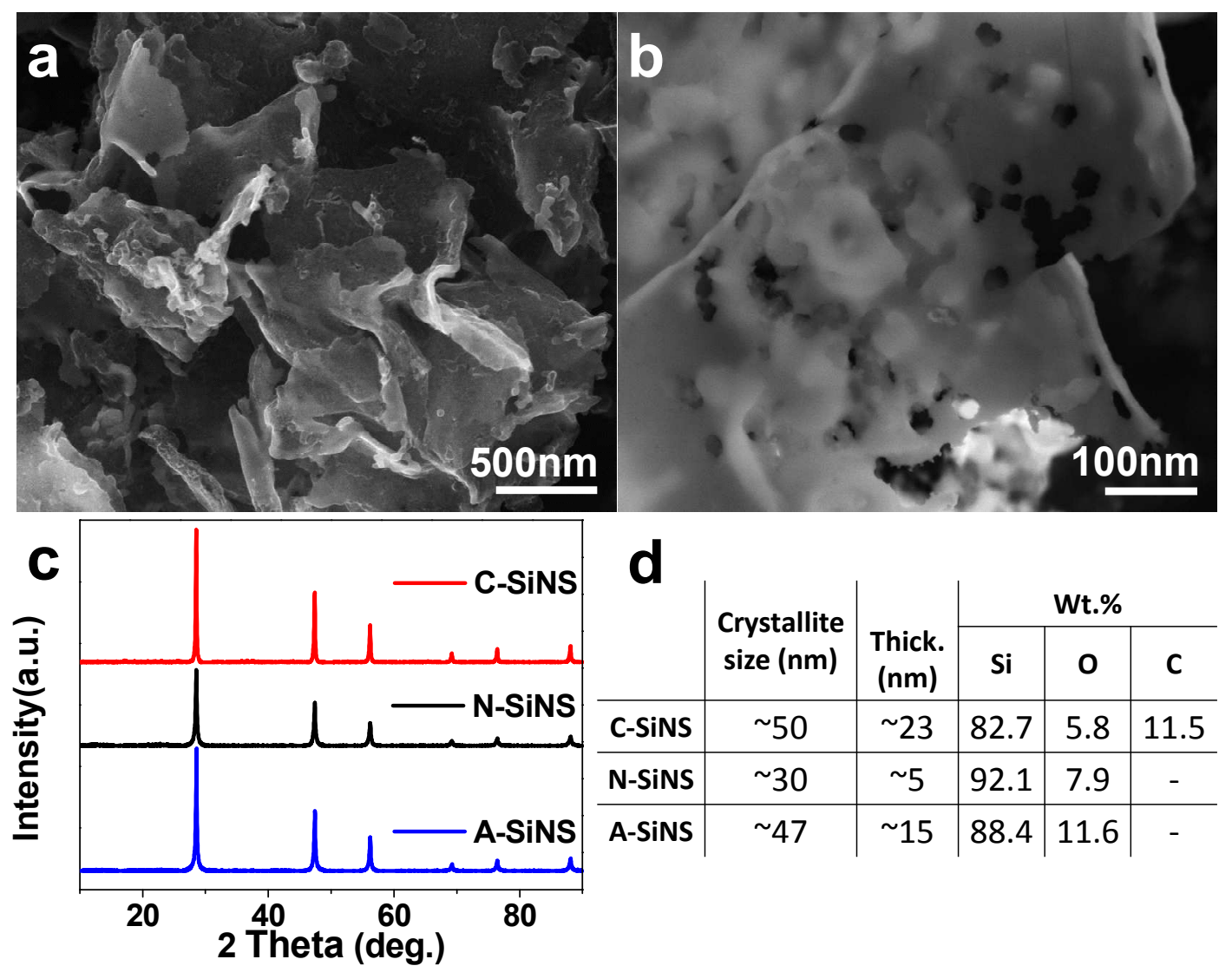

Figure S9. Characterization of A-SiNS. (a-b) SEM images. (c) XRD patterns and (d) Physicial data for three different SiNS samples. 

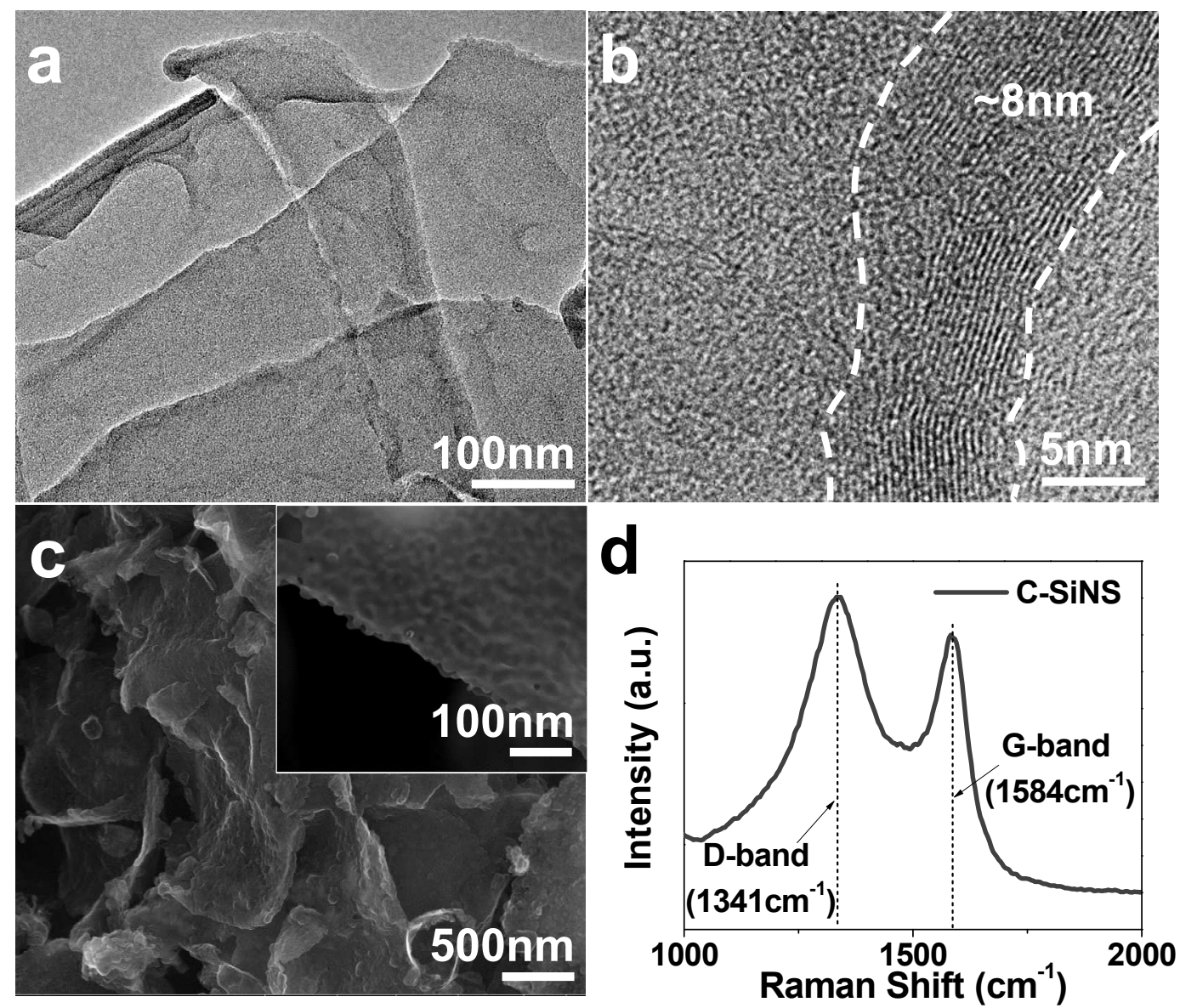

Figure S10. Characterization of C-SiNS. (a-b) TEM images, (c) SEM image (Inset. Magnified SEM image), and (d) Raman spectra of C-SiNS 

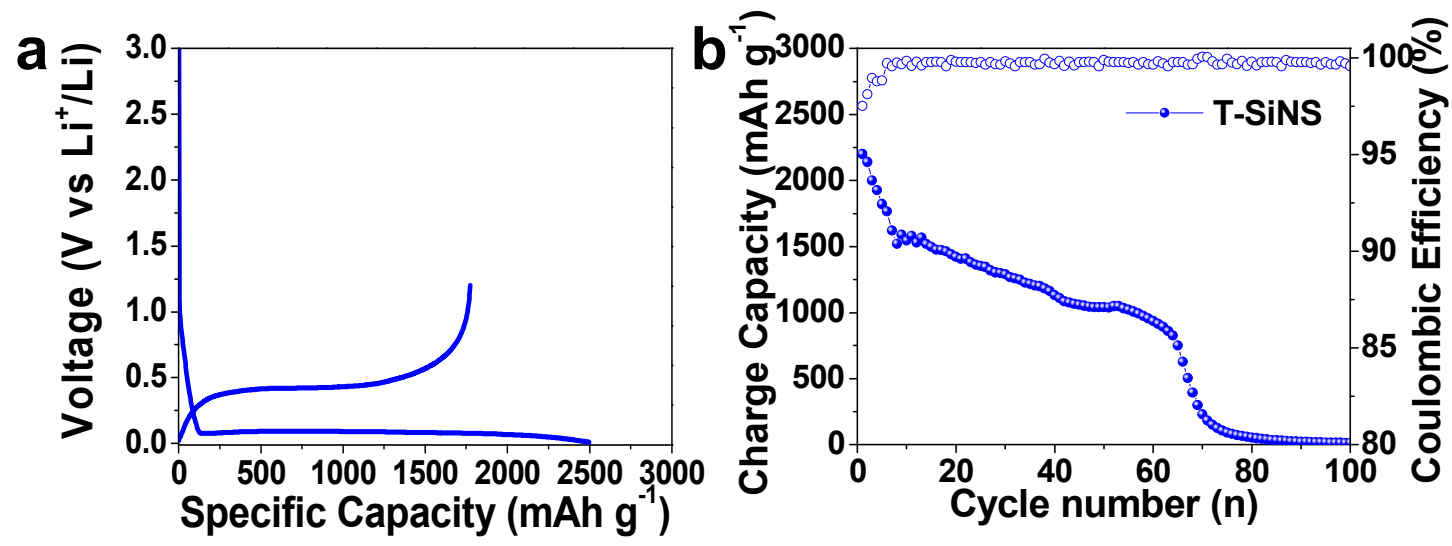

Figure S11. Electrochemical performances of T-SiNS anode. (a) Galvanostatic first cycle discharge/charge voltage profiles at a rate of $0.05 \mathrm{C}$. (b) Cycle retentions at $0.2 \mathrm{C}$ rate of TSiNS anode. 


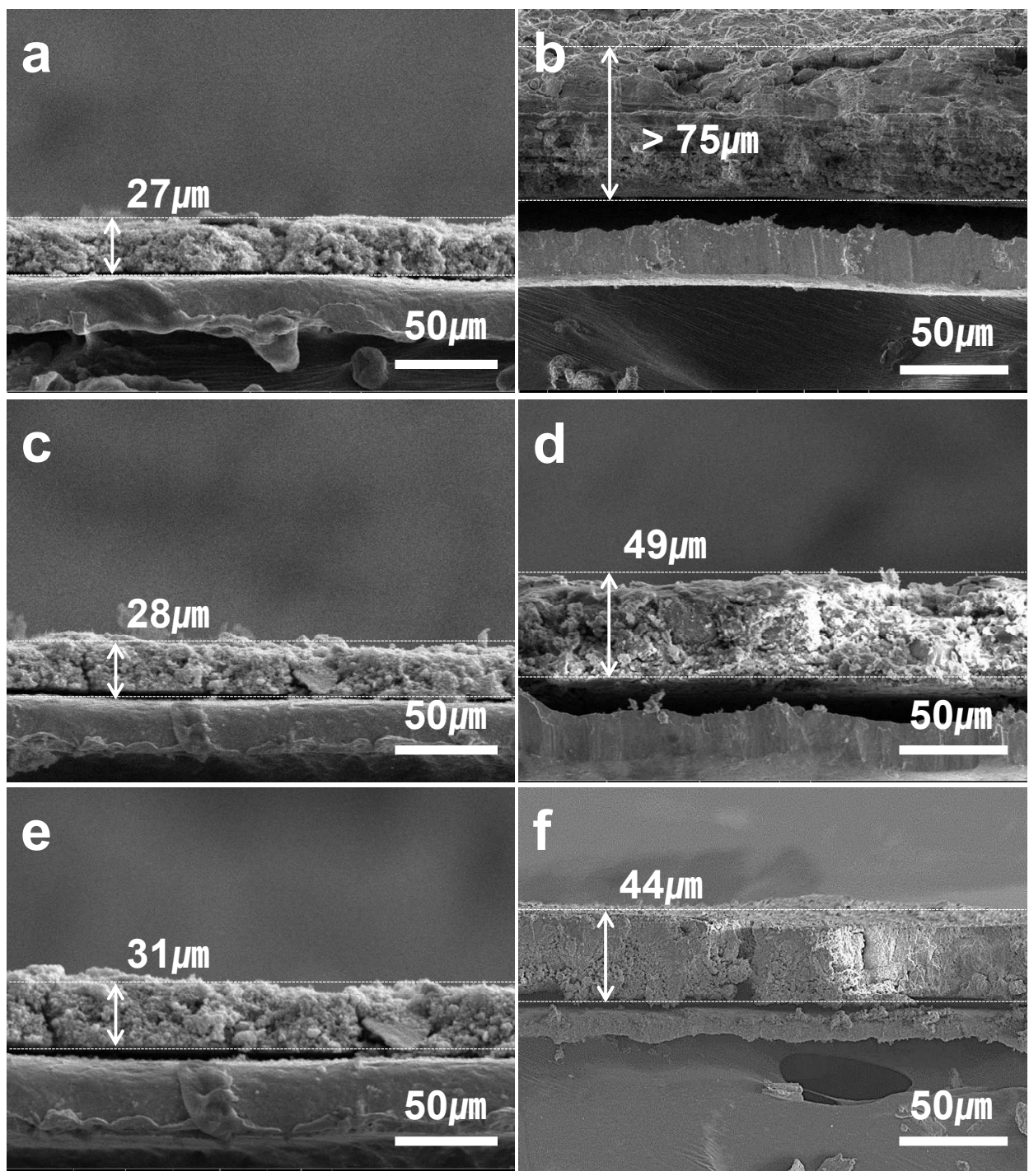

Figure S12. Electrode swelling tests. Cross-sectional SEM images of (a, c, e) pristine and (b, d, f) after 200 cycles at $0.2 \mathrm{C}$ : (a, b) N-SiNS, (c, d) A-SiNS, and (e, f) C-SiNS electrodes. 


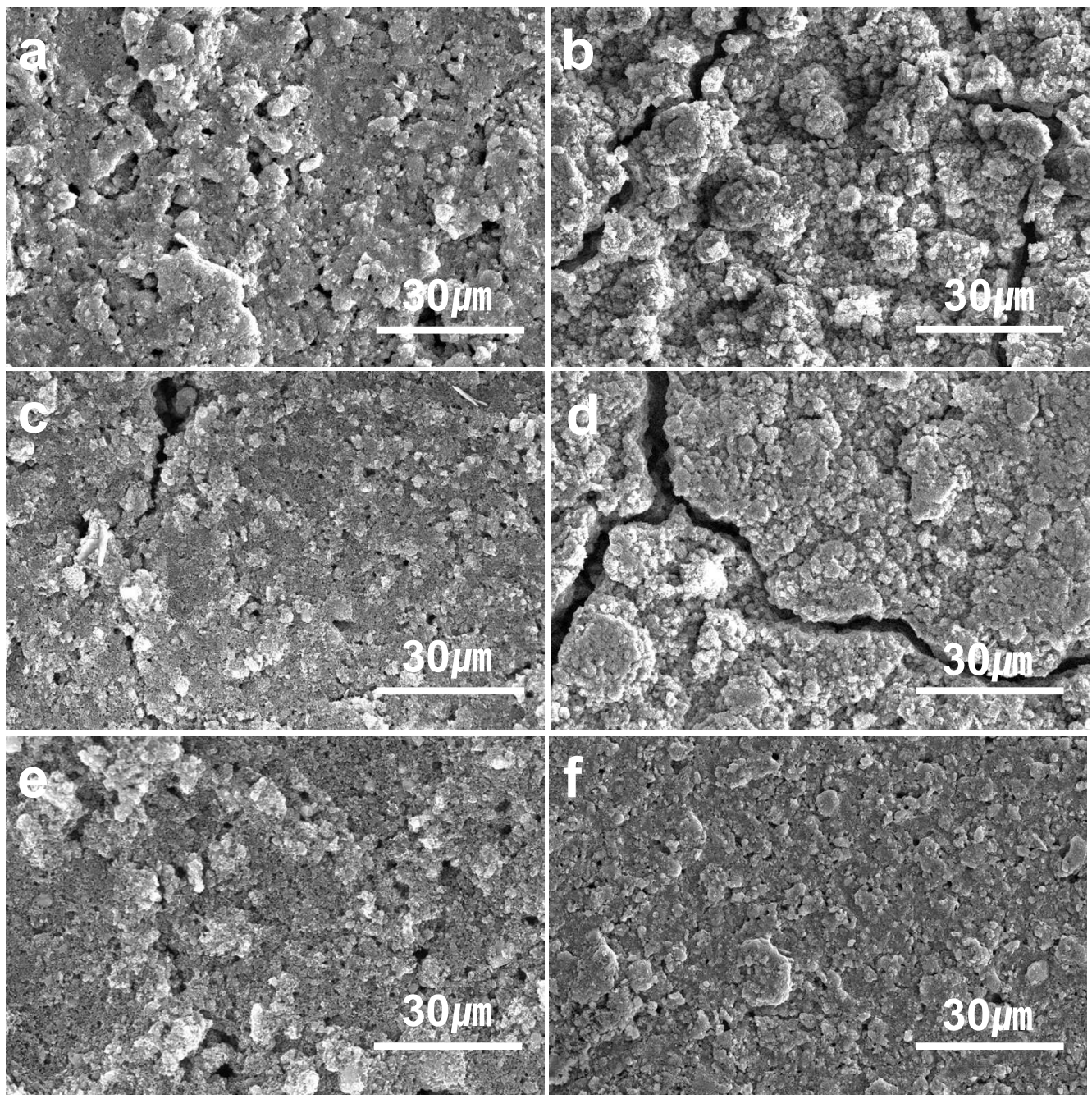

Figure S13. Top view SEM images of (a, c, e) pristine and (b, d, f) after 200 cycles at $0.2 \mathrm{C}$ : (a, b) N-SiNS, (c, d) A-SiNS, and (e, f) C-SiNS electrodes. 

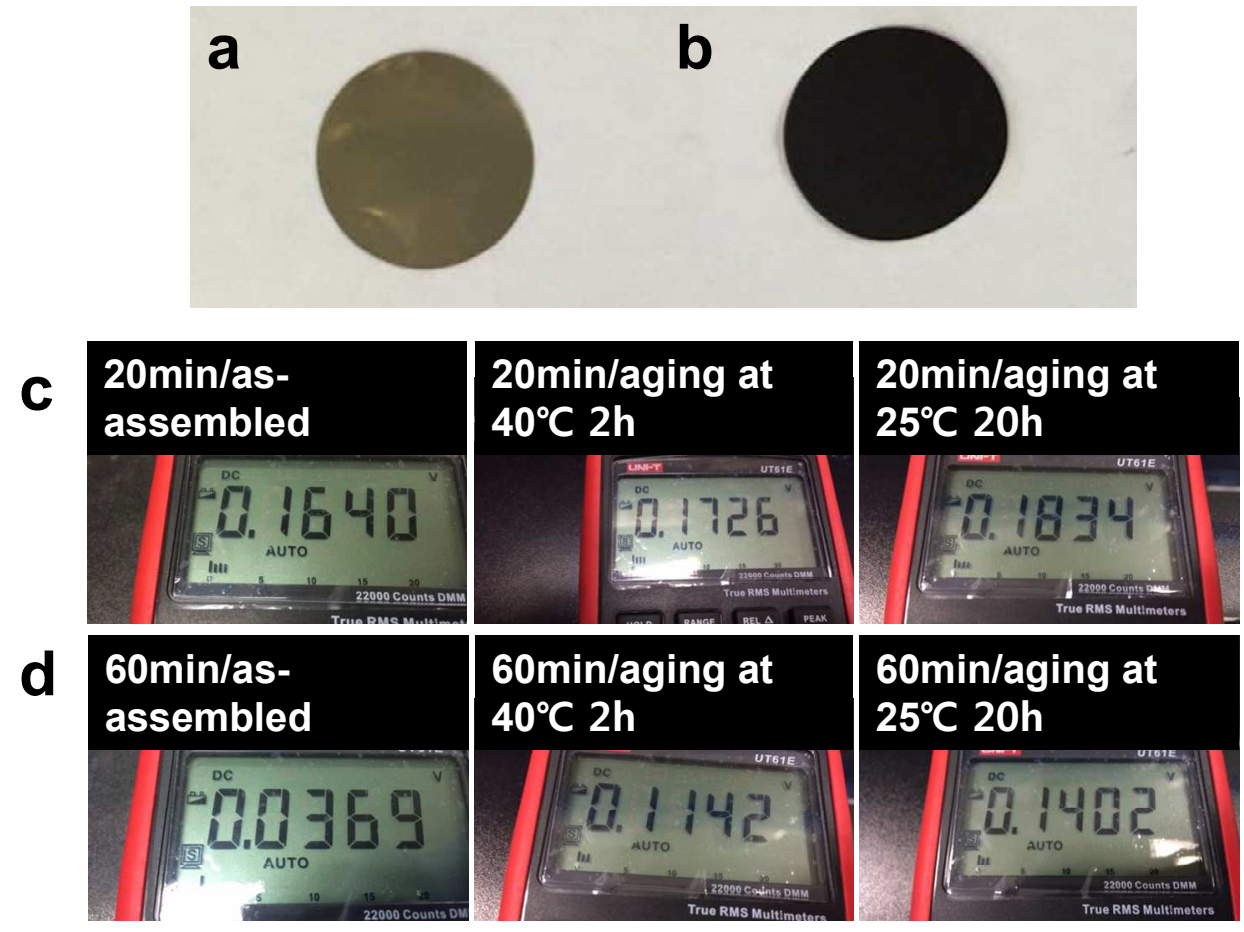

Figure S14. Analysis of prelithiated electrode/cell. Photographs of (a) dark brown-colored pristine A-SiNS electrode and (b) black-colored A-SiNS electrode prelithiated for $20 \mathrm{~min}$. Series of photographs of cell OCV values measured by multimeter at different moments of ASiNS electrode prelithiated (c) for $20 \mathrm{~min}$ and (d) for $60 \mathrm{~min}$. 
Table S1. Summary for electrochemical performances of various nanostructured Si anodes

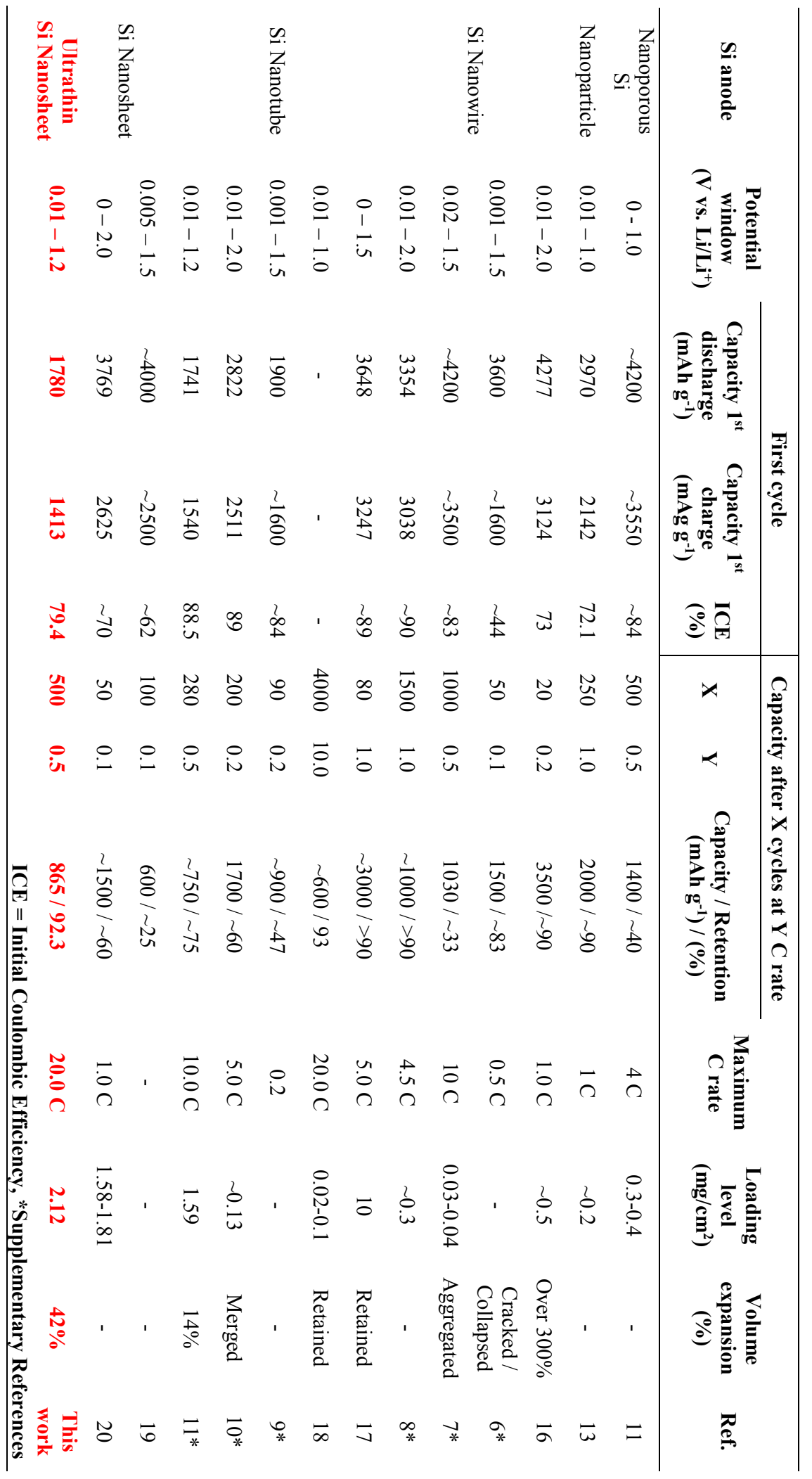




\section{References}

1. Jha, A.; Garade, A. C.; Shirai, M.; Rode, C. V. Metal Cation-Exchanged Montmorillonite Clay as Catalysts for Hydroxyalkylation Reaction. Appl. Clay Sci. 2013, 74, 141-146.

2. Mishra, T.; Parida, K. M.; Rao, S. B. Transition Metal Oxide Pillared Clay: 1. A Comparative Study of Textural and Acidic Properties of Fe(III) Pillared Montmorillonite and Pillared Acid Activated Montmorillonite. J. Colloid Interf. Sci. 1996, 183, 176-183.

3. Turkoz, M.; Savas, H.; Acaz, A.; Tosun, H. The Effect of Magnesium Chloride Solution on the Engineering Properties of Clay Soil with Expansive and Dispersive Characteristics. Appl. Clay Sci. 2014, 101, 1-9.

4. White, J. L. Reactions of Molten Salts with Layer-Lattice Silicates. Nature 1954, 174, 799-800.

5. Ray, S. S.; Okamoto, M. Polymer/Layered Silicate Nanocomposites: A Review from Preparation to Processing. Prog. Polym. Sci. 2003, 28, 1539-1641.

6. Yoo, J. -K.; Kim, J.; Lee, H.; Choi, J.; Choi, M. -J.; Sim, D. M.; Jung, Y. S.; Kang, K. Porous Silicon Nanowires for Lithium Rechargeable Batteries. Nanotechnol. 2013, 24, 424008.

7. Cho, J. -H.; Picraux, S. T. Enhanced Lithium Ion Battery Cycling of Silicon Nanowire Anodes by Template Growth to Eliminate Silicon Underlayer Islands. Nano Lett. 2013, $13,5740-5747$.

8. Ge, M.; Rong, J.; Fang, X.; Zhou, C. Porous Doped Silicon Nanowires for Lithium Ion Battery Anode with Long Cycle Life. Nano Lett. 2012, 12, 2318-2323.

9. Yoo, J. -K.; Kim, J.; Jung, Y. S.; Kang, K. Scalable Fabrication of Silicon Nanotubes and Their Application to Energy Storage. Adv. Mater. 2012, 24, 5452-5456.

10. Lotfabad, E. M.; Kalisvaart, P.; Kohandehghan, A.; Cui, K.; Kupsta, M.; Farbod, B.; Mitlin, D. Si Nanotubes ALD Coated with $\mathrm{TiO}_{2}$, TiN or $\mathrm{Al}_{2} \mathrm{O}_{3}$ as High Performance Lithium Ion Battery Anodes. J. Mater. Chem. A 2014, 2, 2504-2516.

11. Ryu, J.; Choi, S.; Bok, T.; Park, S. Nanotubular Structured Si-Based Multicomponent Anodes for High-Performance Lithium-Ion Batteries with Controllable Pore Size via Coaxial Eletro-Spinning. Nanoscale 2015, 7, 6126-6135. 